Nat Rev Rheumatol. 2013 June ; 9(6): 340-350. doi:10.1038/nrrheum.2013.43.

\title{
The phenotypic and genetic signatures of common musculoskeletal pain conditions
}

\author{
Luda Diatchenko, \\ Regional Center for Neurosensory Disorders, Koury Oral Health Sciences Building, University of \\ North Carolina, Chapel Hill, NC 27599-7455, USA

\section{Roger B. Fillingim,} \\ Public Health Services and Research, College of Dentistry, University of Florida, P.O. Box \\ 100404, Gainesville, FL 32610-0404, USA
}

Shad B. Smith, and

Regional Center for Neurosensory Disorders, Koury Oral Health Sciences Building, University of North Carolina, Chapel Hill, NC 27599-7455, USA

\section{William Maixner}

Regional Center for Neurosensory Disorders, Koury Oral Health Sciences Building, University of North Carolina, Chapel Hill, NC 27599-7455, USA

\section{Abstract}

Musculoskeletal pain conditions, such as fibromyalgia and low back pain, tend to coexist in affected individuals and are characterized by a report of pain greater than expected based on the results of a standard physical evaluation. The pathophysiology of these conditions is largely unknown, we lack biological markers for accurate diagnosis, and conventional therapeutics have limited effectiveness. Growing evidence suggests that chronic pain conditions are associated with both physical and psychological triggers, which initiate pain amplification and psychological distress; thus, susceptibility is dictated by complex interactions between genetic and environmental factors. Herein, we review phenotypic and genetic markers of common musculoskeletal pain conditions, selected based on their association with musculoskeletal pain in previous research. The phenotypic markers of greatest interest include measures of pain amplification and 'psychological' measures (such as emotional distress, somatic awareness, psychosocial stress and catastrophizing). Genetic polymorphisms reproducibly linked with musculoskeletal pain are found in genes contributing to serotonergic and adrenergic pathways. Elucidation of the biological mechanisms by which these markers contribute to the perception of pain in these patients will enable the development of novel effective drugs and methodologies that permit better diagnoses and approaches to personalized medicine.

(C) 2013 Macmillan Publishers Limited. All rights reserved

Correspondence to: L. Diatchenko, luda@unc.edu.

All authors contributed equally to each stage of the preparation of this manuscript for publication.

Competing interests

L. Diatchenko, R. B. Fillingim, S. B. Smith and W. Maixner declare associations with Algynomics. Please see the article online for details of the relationships.

Supplementary information is linked to the online version of the paper at www.nature.com/nrrheum 


\section{Introduction}

Chronic pain is a silent epidemic that affects hundreds of millions of individuals worldwide, resulting in great personal suffering and social burden, in terms of lost productivity and financial cost. ${ }^{1}$ Progression of acute to chronic pain is now known to adhere to the basic principles of disease processes affecting both the central and peripheral nervous systems. Among the most prevalent chronic or persistent pain conditions are those affecting the musculoskeletal system. The term 'musculoskeletal pain conditions' encompasses a large number of pain conditions; however, this Review will focus on the biopsychosocial and genetic factors that contribute to chronic low back pain (LBP), painful temporomandibular joint disorders (TMD), fibromyalgia and chronic widespread pain (CWP). CWP is a defining feature of fibromyalgia that is commonly assessed in population-based studies using surveys - rather than by physical exam —and, like fibromyalgia, is characterized by pain in contralateral body quadrants and the axial skeleton lasting at least 3 months. Collectively, these painful musculoskeletal conditions are poorly understood from a mechanistic perspective, highly comorbid, and frequently observed in the general population.

In this Review, we provide a brief overview of the epidemiology, phenotypic characteristics and genetic factors that are associated with or descriptive of these conditions. We will also address, from a conceptual perspective, how our emerging understanding of the demographic, biopsychosocial, environmental and genetic factors can be integrated into a heuristic model that seeks to explain the pathophysiological processes that underlie these conditions. Using the knowledge gleaned, the model can be further tested and revised in a manner that will improve our ability to diagnose and treat patients suffering from these common musculoskeletal conditions. Although not specifically presented herein, our impression is that the proposed heuristic model can be applied to other musculoskeletal pain conditions such as osteoarthritis, which is a disease better understood from a pathophysiological perspective than LBP, fibromyalgia, CWP and TMD, but is beyond the scope of this Review.

\section{Epidemiology}

The epidemiology of LBP, CWP, fibromyalgia and TMD has been fairly well characterized in the general population; 2,3 the incidence of these conditions is high. For LBP, the point prevalence estimates range from $8-44 \%$, and at least $50 \%$ of the general population experience LBP in their lifetime. ${ }^{2,3}$ In children and adolescents, new-onset LBP increases with age, from $12.5 \%$ at age 12 to $24.1 \%$ at age $15 .{ }^{2,3}$ Prevalence estimates for CWP seem to be consistent between US and Western European populations ranging from 11-13\%., On the other hand, fibromyalgia shows a wider range of prevalence values, from $0.7 \%$ in Danish women to $10.5 \%$ in Norwegian women. ${ }^{2,3}$ The frequency of TMD has been estimated at $12 \%$, with a female to male ratio of $2: 1$ in the general population and $8: 1$ in the clinical setting, and the annual incidence of first-onset TMD has been estimate to be around 3\%. ${ }^{2,3}$ In the ongoing Orofacial Pain Prospective Evaluation and Risk Assessment (OPERRA) study, ${ }^{4}$ the prevalence of TMD was observed to increase with age, female 
gender (3:1), and was more frequent among non-Hispanic white individuals compared with black, African American and Hispanic individuals. ${ }^{3}$ In contrast to other common musculoskeletal pain conditions, ${ }^{2}$ the expected effect of a socioeconomic gradient on the prevalence of TMD - that is, association between lower socioeconomic status and higher prevalence of the condition-was not observed. ${ }^{3}$ The high prevalence of TMD and other musculoskeletal conditions, including LBP, CWP and fibromyalgia, explains the high personal and societal costs of treating such chronic pain conditions. ${ }^{1}$

Several risk factors have been associated with the development of these musculoskeletal pain conditions. In addition to demographic factors, two intrinsic phenotypic domains are associated with the risk of developing painful musculoskeletal, pain amplification (increased pain sensitivity) and psychological distress. ${ }^{4,5}$ The outcomes of both case-control and longitudinal studies have provided evidence that both the prevalence and onset of musculoskeletal pain conditions are associated with augmentation of pain processing, which might be attributable to impairments in inhibitory systems of the central nervous system (for example, diffuse noxious inhibitory controls or conditioned pain modulation) and/or the sensitization of peripheral or central nervous system processes that code pain information (such as temporal summation of pain). ${ }^{6-9}$ Psychologically-assessed factors such as enhanced somatic awareness (the perception and interpretation of information from the senses and proprioception), anxiety, depression, perceived stress and catastrophizing have also been associated with increased prevalence and risk of first onset of musculoskeletal pain conditions. ${ }^{2,10}$ Among these psychologically-assessed factors, somatic awareness is emerging as a potent predictor of the development of musculoskeletal pain conditions. These associations might result from the fact that, as a phenotype, somatic awareness reflects both pain or sensory amplification and psychological distress risk domains.

A variety of personal behaviours, such as smoking, ${ }^{2,11}$ and uncontrollable events, such as injuries, ${ }^{11-13}$ represent environmental exposures that can influence biological pathways that lead to the manifestation and maintenance of musculoskeletal pain conditions. ${ }^{4,5}$ These exposures are thought to have cumulative effects over time (that is, with age), are modified by gender, and the intensity of exposure is probably influenced by socioeconomic status.

Body mass index is positively associated with many musculoskeletal pain conditions, which might result from a mechanical stress on the musculoskeletal system and/or reflect an abundance of adipose tissue that represents a source of proinflammatory and propain cytokines. ${ }^{2,14}$ An understanding of the effects of smoking on painful musculoskeletal pain conditions is also beginning to emerge. Smoking has been associated with an increased prevalence of LBP and fibromyalgia, ${ }^{2}$ and a lifelong history of smoking has been reported to be associated with an increased likelihood of TMD. ${ }^{11}$ The mechanisms by which smoking influences musculoskeletal pain conditions are unknown, but smoking might prime of the immune system producing a bias towards a proinflammatory state. Another environmental exposure that is associated with increased risk of persistent musculoskeletal pain is physical injury, including damage resulting from elective surgical procedures. ${ }^{15}$

The mechanisms by which these environmental exposures influence the prevalence and likelihood of development of persistent musculoskeletal pain conditions are poorly understood. However, evidence supports the view that the expression of an individual's 
genetic background, which is temporally and dynamically influenced by environmental exposures, produces intermediate phenotypes or endophenotypes that contribute to conditions such as LBP, CWP, fibromyalgia and TMD. ${ }^{4,5,16,17}$ Endophenotypes, such as pain amplification and psychological distress, represent measurable constructs that are linked to the pathophysiological mechanisms that result in the perception and reporting of clinical pain. Endophenotypes are situated between genotype and the syndrome, and thus are more proximal to the biological pathway. ${ }^{18}$ Key intermediate phenotypes, genetic polymorphisms and the effects of environmental exposures on genetically-mediated phenotypes (that is, gene-environment interactions) are described in the following sections.

\section{Assessment of musculoskeletal pain}

In addition to quantifying clinically important endpoints, optimal characterization of musculoskeletal pain conditions should identify potential pathophysiologic mechanisms, which requires assessment of multiple phenotypic domains beyond simple determination of clinical pain intensity. First, several dimensions of the individual's clinical pain should be assessed. Second, as recommended by the Initiative on Methods, Measurement, and Pain Assessment in Clinical Trials (IMMPACT), ${ }^{19}$ important comorbid symptom domains need to be evaluated, including physical and psychological functioning. Third, endophenotypes should be examined, including quantitative sensory testing (QST), in which the intensity of stimuli needed for sensory perception is measured to assess the functioning of the sensory nervous system to identify alterations in pain perception and pain modulation, and assessment of autonomic function to determine physiologic changes that could contribute to symptomatology.

\section{Assessing pain perception and interference}

As alluded to previously, in addition to obtaining information regarding the clinical severity of the patient's symptoms, pain assessment should ideally provide clues regarding underlying pathophysiologic mechanisms. Several aspects of pain should be quantified (Table 1): pain severity, both the intensity and the unpleasantness of pain, can be independently assessed with specific numerical rating or visual analog scales, or with verbal descriptor measures; ${ }^{20,21}$ temporal qualities of the pain (episodic or continuous, daily variability of pain) are best assessed using ecological momentary assessment via electronic devices $;^{22}$ perceptual qualities of the pain, assessed using verbal descriptor scales, such as the McGill pain questionnaire, ${ }^{23}$ based on the notion that different sensory qualities of pain reflects distinct underlying mechanisms. ${ }^{24,25}$

Assessment of other phenotypic domains is important, particularly physical and psychological function, as previously recommended by IMMPACT. ${ }^{19}$ Physical function (or disability), can be measured using patient-reported instruments or performance-based methods, such as exercise tests and functional capacity evaluations. Using both types of measure is preferably, because patient-reported and performance-based measures are weakly correlated with each other in chronic pain populations. ${ }^{26}$ Functional capacity evaluations have been widely implemented as performance-based indices of physical function in patients with LBP. ${ }^{27}$ These functional measures have been associated with patient self-reported 
disability and psychological factors, ${ }^{26}$ and are sensitive to treatment effects. ${ }^{27,28}$ Exercisebased functional assessments have revealed that patients with fibromyalgia have poorer performance in aerobic and strength measures compared with healthy controls, ${ }^{29}$ and functional performance has been associated with clinical pain, pain sensitivity, brain responses to pain, and cognitive performance in this condition. ${ }^{28,30,31}$ More ecologically valid performance-based methods that objectively quantify physical activity in the patient's natural environment have become increasingly utilized, such as actigraphy, which uses an accelerometer to assess real-time physical activity. ${ }^{32}$ Actigraphy has revealed reduced physical activity in patients with fibromyalgia, which correlated with patient-reported activity. 31,33

Several types of self-report instruments can be used to assess function and disability in musculoskeletal pain (Supplementary Table 1). These include instruments designed for specific musculoskeletal pain conditions, such as the Roland Morris Disability Questionnaire and the Oswestry Disability Index for LBP, the Fibromyalgia Impact Questionnaire and it's revised version, and the Jaw Function Limitation Scale, which assesses the functional status of the masticatory system related to TMD. In addition, certain patient-reported instruments provide a general measure of pain-related interference with liferelevant activities, such as the Brief Pain Inventory, the Graded Chronic Pain Scale and the Multidimensional Pain Inventory; others represent generic measures of functional status or disability, including the Health Assessment Questionnaire, the Disability Rating Index, and the physical functioning and role limitations scales from the Short-form Health Survey with only 36 questions $\left(\mathrm{SF}-36^{\circledR}\right)$.

At present, the diagnosis of musculoskeletal pain conditions relies largely on signs and symptoms, which convey limited information regarding pathophysiology, thereby providing minimal information to facilitate identification of targets for novel treatments.

Endophenotypes are more proximal to the biological perturbation; ${ }^{18}$ therefore, both pain amplification and psychological domains, which are more closely linked with pathophysiological mechanisms than signs and symptoms of clinical pain, require careful measurement and analysis.

\section{Psychological domain assessment}

Within the psychological domain, abundant evidence indicates altered psychological function in in patients with musculoskeletal pain, including increased levels of emotional distress, somatic awareness, psychosocial stress, and maladaptive coping. ${ }^{10,34,35}$ Important to note is that characterizing factors as 'psychological' refers to the method of assessment rather than to the underlying pathophysiologic mechanism. For example, somatic awareness is typically assessed using 'psychological questionnaires'; however, this construct actually reflects altered peripheral and central nervous system processing of somatosensory stimuli and overlaps considerably with sensory amplification as assessed using QST (described in the following section). Thus, we refer to 'psychological' factors primarily based on their level of assessment rather than on the mechanisms contributing to such domains. 
Although psychological symptomatology is often interpreted as a consequence of chronic pain, prospective studies suggest that pre-morbid psychological dysfunction represents a risk factor for future development of chronic pain. ${ }^{36,37}$ For example, higher levels of psychological distress, somatic symptoms (that is, bodily sensations appraised as unpleasant, abnormal or worrisome by the patient), illness behaviour, sleep disturbance and childhood adversity predicted onset of CWP and LBP. ${ }^{37-40}$ Furthermore, pre-existing somatic awareness, health anxiety, perceived stress, and negative mood predicted onset of TMD. ${ }^{41,42}$ Moreover, similar psychosocial factors predict transition from acute to chronic musculoskeletal pain. ${ }^{37,43,44}$ Therefore, psychosocial functioning is a critical component of phenotypic characterization of musculoskeletal pain conditions, and several psychosocial domains should be incorporated into patient assessments: global psychological symptoms, including negative affectivity and emotional distress; somatic awareness; life events and perceived psychosocial stress; pain-related cognitions (for example, fear avoidance or catastrophizing); and pain coping (see Table 1).

\section{Pain sensitivity and amplification assessment}

Like the psychological intermediate phenotypes, the endophenotypes associated with pain amplification represent measurable constructs that are more closely related to the pathophysiological mechanisms than pain intensity; ${ }^{18}$ therefore, these endophenotypes are linked with pathophysiological mechanisms that produce the signs and symptoms associated with LBP, fibromyalgia, CWP, and TMD. QST methods ascertain multiple endophenotypes of potential relevance to musculoskeletal pain conditions by assessing the perceptual and/or physiological responses to systematically applied and quantifiable sensory stimuli for the purpose of characterizing somatosensory functioning. A systematic methodology for QST in clinical studies has been described and validated, ${ }^{45}$ and investigators have used QST as a method of subgrouping patients with neuropathic and musculoskeletal pain, ${ }^{46,47}$ including fibromyalgia and TMD. ${ }^{48}$

As reviewed in $2010,{ }^{8}$ considerable evidence indicates multiple phenotypic patterns of altered somatosensory function among patients with musculoskeletal pain syndromes. Four specific domains of sensory function should be targeted when performing QST in CWP (Table 1). First, nonpain somatosensation, reduced sensitivity to nonpainful thermal and mechanical stimuli, has been reported in several chronic pain conditions, ${ }^{49-51}$ implying that the central nervous system might be imbalanced toward processing of painful stimuli. Second, generalized hyperalgesia, increased pain in response to previously painful stimuli, has also been reported in musculoskeletal pain. Numerous studies, using multiple stimulus modalities, including muscle-pain assessment using pressure devices (such as algometers) or methods that evoke transient muscle ischaemia, report reduced pain thresholds and increased pain ratings in response to suprathreshold stimuli in musculoskeletal pain conditions, indicating generalized hyperalgesia; $6,52,53$ Third, pain facilitatory function, most commonly assessed by quantifying temporal summation of pain, is an increased perception of pain that accompanies repetitive or sustained painful stimulation at a constant stimulus intensity. Temporal summation is thought to result from increased excitability of dorsal horn transmission neurons mediated by the $N$-Methyl-d-aspartate (NMDA)-receptor, a transient form of central sensitization also known as windup. ${ }^{54,55}$ Enhanced temporal summation of 
thermal and mechanical pain has been reported in fibromyalgia, LBP and TMD. ${ }^{7,56}$ Finally, pain inhibitory function should also be assessed. The method most frequently used to measure pain inhibitory function is conditioned pain modulation (CPM), also known as diffuse noxious inhibitory controls (DNIC), ${ }^{57}$ which determines the extent to which the perceptual intensity of one painful stimulus is reduced by the application of a second painful stimulus at a remote body site. Using CPM, reduced pain inhibitory function has been reported in musculoskeletal pain conditions, including fibromyalgia and TMD. ${ }^{58,59}$

\section{Assessment of autonomic function}

Dysregulation of the autonomic nervous system represents another endophenotype of relevance to musculoskeletal pain conditions. ${ }^{60,61}$ Increased resting sympathetic nervous system tone coupled with deficient responses to postural or exercise challenges mediated by the sympathetic nervous system have been reported in fibromyalgia. ${ }^{62,63}$ Furthermore, decreased heart rate variability has been observed in fibromyalgia, potentially signalling reduced parasympathetic and greater $\beta$-adrenergic tone, ${ }^{63,64}$ and these patients also show blunted sensitivity to the baroreceptor reflex (or baroreflex), the negative feedback reflex by which elevated blood pressure reduces heart rate. ${ }^{65,66}$ In addition, reduced high-frequency heart rate variability, suggesting sympathetic dominance, was observed in patients with chronic LBP with at least moderate patient-perceived disability, but not among those reporting a low degree of disability ${ }^{67}$ Heart rate and blood pressure responses during orthostatic challenges are also reduced in fibromyalgia. ${ }^{68}$ Differences in autonomic function owing to central nervous system dysregulation in patients with fibromyalgia is further indicated by reduced plasma and cerebrospinal fluid catecholamine responses to stressors such as exercise or hypoglycemia; ${ }^{62,69-71}$ a similar pattern of autonomic dysfunction in patients with TMD has been reported. ${ }^{72}$ An extensive protocol for autonomic testing was described in 2011, ${ }^{72}$ which included cardiovascular measures (blood pressure, heart rate, and heart rate variability) at rest, as well as in response to orthostatic challenge and psychological stress.

\section{Identifying homogeneous patient subgroups}

Because musculoskeletal pain reflects a heterogeneous group of conditions, advanced methods of data analysis need to be applied to the multiple phenotypic domains to reveal more homogeneous subgroups within the musculoskeletal pain population. The discussion in the previous sections outlines the multiple phenotypic domains that represent important targets for assessment in patients with CWP. Each domain can be interpreted independently; however, the findings can be examined across domains in order to identify patient profiles that might reflect differing pathophysiologic mechanisms and distinct underlying genetic architectures. Statistical approaches can be applied to identify profiles across phenotypic domains. For example, cluster analysis, a set of statistical classification methods that identifies groups of people that show similar characteristics across one or more phenotypic measure, has previously been applied to QST responses in healthy individuals, ${ }^{73}$ demonstrating that people can be stratified based on responses to multiple stimulus modalities. Several studies have reported such analyses in fibromyalgia, LBP and TMD, including clustering of patients according to physical and psychosocial symptoms ${ }^{74-77}$ QST 
responses and comorbid symptoms, ${ }^{47,78}$ and biological markers and psychologicallyassessed factors. ${ }^{79}$ Although the nature of the subgroups identified varies across studies owing to differences in the phenotypes used to generate the clusters, these studies demonstrate the feasibility of deconstructing the heterogeneous musculoskeletal pain population into more homogeneous subgroups. Other methods of classification are available, including latent class analysis and machine learning approaches. ${ }^{80,81}$

The genetic and associated molecular pathways that underlie the identified disease subgroups have not yet been adequately assessed. Nevertheless, the identification of subgroups using quantitative measures of endophenotypes, such as QST, coupled with the identification of the molecular profiles that underlie specific subgroups holds great promise in developing mechanistic diagnostic protocol and identifying novel biological targets and pathways for both pharmacological and nonpharmacological therapeutic interventions.

\section{Genetic markers of chronic pain}

The relative importance of genetic factors in human musculoskeletal pain conditions is becoming clearer. Heritability of these conditions seems to be comparable to other common disorders. For example, the heritability for neck pain, pain reported at any site, and clustering of symptoms associated with fibromyalgia is estimated to be $44 \%, 8246 \%, 83$ and $51 \%,{ }^{84}$ respectively. Thus, around $50 \%$ of the risk of developing chronic pain conditions is driven by genetic background.

\section{Genetic association studies in humans}

We performed a formal review of all genetic associated studies in TMD, fibromyalgia, LBP and CWP reported up to August 2012. 20 loci have been associated with at least one of the conditions (Supplementary Table 2). Of these 20 loci, six genes or gene clusters have been repeatedly associated with at least one of these chronic pain disorders (Table 2); the other 14 genes have been associated in a single study and should be considered preliminary findings until they have been independently replicated. These associations have implicated two major neurotransmitter pathways in musculoskeletal pain. The first is the adrenergic pathway, in which COMT, the gene encoding the enzyme catechol O-methyltransferase that is responsible for the catabolism of catechol neurotransmitters such as epinephrine, norepinephrine, and dopamine, is the most frequently associated with chronic musculoskeletal pain conditions. Most studies of COMT report that an increased risk of chronic pain is associated with a nonsynonymous Val158Met (rs4680) polymorphism, which encodes a protein with lower enzymatic activity. ${ }^{85-89}$ Other groups have expanded the functional locus to three major haplotypes encompassing the gene, which modify expression and activity of catechol O-methyltransferase; the low pain sensitivity haplotype is associated with the highest enzymatic activity and confers protection against chronic pain. ${ }^{16,90,91}$

Two nonsynonymous SNPs in the $\beta_{2}$-adrenergic receptor gene (ADRB2), Arg16Gly (rs 1042713) and Gln27Glu (rs1042714), are associated with an increased risk of fibromyalgia and CWP. ${ }^{85,92,93}$ As with COMT, haplotype variants, which regulate $\beta_{2^{-}}$ 
adrenergic receptor expression and internalization, are associated with differences in susceptibility to chronic pain..$^{92,94}$

The second neurotransmitter pathway that has been associated with chronic functional pain syndromes is the serotonin pathway, including the 5-hydroxytryptamine receptor $2 \mathrm{~A}$ (5HT-2A, encoded by HTR2A) and 5HT transporter (5HTT, also known as sodiumdependent serotonin transporter, encoded by $S L C 6 A 4)$. A 44bp insertion/deletion polymorphism in the promoter region of SLC6A4 is most frequently associated with both risk of chronic pain conditions and related endophenotypes. The 'short' (deletion) allele has been found to increase risk of fibromyalgia, ${ }^{95-97}$ although the 'long' (insertion) variant has been associated with a higher risk of TMD in a Japanese cohort. ${ }^{98}$ In another study in TMD, a link between the promoter region polymorphism and this condition was observed as well as an association with a variable nucleotide tandem repeat polymorphism in intron 2 of SLC6A4 ${ }^{99}$ Studies of HTR2A are more consistent, as the silent $102 \mathrm{~T}>\mathrm{C}$ polymorphism has been repeatedly shown to increase risk of both fibromyalgia, ${ }^{100,101}$ and TMD. ${ }^{102}$

A possible immunological component in a subset of patients with fibromyalgia prompted the investigation of the involvement of HLA antigens in this condition. Several MHC class I and II antigens, including HLA-B58, HLA-DR4, HLA-DR5 and HLA-DR8, have been associated with chronic pain, ${ }^{103,104}$ although these findings have not been consistently replicated. ${ }^{105}$ Inflammatory mechanisms have also been investigated, with notable findings for the $\mathrm{a}_{1^{-}}$ antitrypsin gene, SERPINA1; in Spanish ${ }^{106}$ and $\mathrm{US}^{107}$ cohorts, the $\mathrm{Z}$ allele of SERPINA1, which enables production of only limited amounts of $a_{1}$-antitrypsin, was more frequent in patients with fibromyalgia than in the general population.

Candidate genes have also been tested for association with traits and outcome measures studied in conjunction with chronic pain disorders. Several genes have shown association with such phenotypes (Supplementary Table 2), some repeatedly (Table 1), including the four previously described neurotransmitter pathway genes associated with disease status. The adrenergic pathways genes $A D R B 2$ and COMT have been associated with numerous endophenotypes believed to underlie chronic pain disorders, including autonomic dysregulation, ${ }^{94}$ alterations in pain processing and modulation, ${ }^{16,108}$ sleep dysfunction, ${ }^{85,93}$ and anxiety. ${ }^{94,109}$ The serotonergic pathway genes SLC6A4 and HTR2A have been associated with personality and affective traits such as somatic awareness, ${ }^{99,110}$ depression ${ }^{95}$ and anxiety, ${ }^{110}$ which contribute to risk of chronic pain.

\section{Evidence from gene sequencing}

Complex pain conditions are by definition attributable to multiple genetic and environmental influences. Genetic association studies have proven successful in exploring the relationship between common genetic polymorphisms and common traits and diseases, but they have not yet accounted for the genetic component of variance caused by rare genetic variants, with minor allele frequencies of $5 \%$ or less. Deep sequencing is already proving successful in identifying rare variants associated with fibromyalgia. ${ }^{111}$ Family trios (affected probands and their parents) were re-sequenced at the $M E F V$ gene locus, where known mutations result in familial Mediterranean fever, an autosomal recessive disorder that shares symptoms such 
as widespread body pain and tenderness with fibromyalgia. ${ }^{111} \mathrm{~A}$ total of 10 rare alleles with missense polymorphisms, one of which was present in $15 \%$ of the probands, occurred across the gene locus, and preferential transmission of these rare alleles from heterozygous parents to affected offspring indicated these alleles are all associated with risk of fibromyalgia. ${ }^{111}$ These results indicate that rare variants are strong risk factors for complex disease traits and might underlie disease in a subset of patients with a common pain condition like fibromyalgia.

Although the application of deep sequencing to the study of common pain conditions remains largely on the horizon, studies are in progress that are designed with this emerging technology in mind. ${ }^{4,91,112}$ Prioritizing candidate genes with roles in pain for re-sequencing will be important given the current costs associated with the technique, and such efforts will continue to be informed by linkage, candidate gene association studies, and genome-wide association studies. ${ }^{113}$ Because rare variants are likely to have substantially greater effects on a pain phenotype than common polymorphisms, they could be responsible for more severe manifestations of the pain condition and thus might be more readily identified in extreme cases derived from existing population-based studies. ${ }^{17}$

\section{Translational value of genotypic markers}

Identification of genotypic markers of chronic pain has substantial value in translational medicine. Findings from research into complex cardiovascular disorders show that the genetic loci at which rare mutations cause monogenic familial cardiovascular disorders overlap considerably with common genetic variants identified in association studies from related common, complex cardiovascular disorders; ${ }^{114}$ thus genetic variants in these pathways are targets for pharmacotherapy for these disorders. An illustration of how the results from human genetic associations can contribute to the process of understanding and development of treatments for a common pain condition is presented in Figure 1. Catechol O-methyltransferase represents an essential component of the nervous system that regulates catechol neurotransmitters levels and thus homeostasis in response to physical and psychological stressors. A series of studies in humans and animal models have linked catechol O-methyltransferase to pain perception. A genetic variation in the COMT gene correlates with the sensitivity to noxious stimuli in both humans, ${ }^{16,90,115}$ and in mice, ${ }^{116}$ as well as the risk and severity of chronic pain conditions, as we have discussed (Table 2).

These findings led to the identification of new drug targets in animal models, ${ }^{117}$ which have been translated into a novel pharmacological treatment for TMD. ${ }^{118}$

Three major haplotypes of COMT, designated as low, average or high pain sensitive, have been identified based on a carrier's response to experimental pain stimuli. ${ }^{16}$ These three haplotypes account for $11 \%$ of the variability to experimental pain sensitivity in young women and are predictive of the risk of onset of a common musculoskeletal pain disorder (that is, TMD). The low pain sensitive haplotype corresponds with higher levels of catechol O-methyltransferase enzymatic activity than the average or high pain sensitive haplotypes, ${ }^{119}$ suggesting that greater turnover of catechol neurotransmitters in individuals with the low pain sensitive haplotype increases their resistance to pain. Indeed, a 2010 
literature review revealed that $C O M T$ haplotypes were consistently associated with pain sensitivity in multiple studies. ${ }^{120}$

The pharmacological inhibition of catechol O-methyltransferase in rats results in mechanical and thermal hypersensitivity, which is reversed by the non-selective $\beta$-adrenergic antagonist propranolol or by the combined administration of selective $\beta_{2}$-adrenergic and $\beta_{3}$-adrenergic antagonists. ${ }^{117}$ By contrast, the administration of $\beta_{1}$-adrenergic, $a$-adrenergic, or dopaminergic receptor antagonists failed to alter catechol-O-methyltransferase-dependent pain sensitivity. ${ }^{117}$ These data provide the first direct evidence that low catechol Omethyltransferase activity leads to increased pain sensitivity via a $\beta_{2} / \beta_{3}$-adrenergicdependent mechanism, and suggest that pain conditions associated with low catechol Omethyltransferase activity and/or elevated catecholamine levels can be treated with pharmacological agents that block both $\beta_{2}$-adrenergic and $\beta_{3}$-adrenergic receptors. This finding led to the hypothesis that propranolol, a nonselective $\beta$-adrenergic antagonist that is widely used clinically for treatment of hypertension, could be an effective treatment for chronic pain conditions in a manner that is dependent on the patient's COMT haplotypes.

To test this hypothesis, a double-blind, placebo-controlled, two-period crossover pilot study of efficacy of propranolol was conducted in 40 female patients with TMD. ${ }^{118}$ The outcomes of this study demonstrated that propranolol, independent of COMT genotype, markedly reduced a composite measure of clinical pain. ${ }^{118} \mathrm{~A}$ trend towards decreasing experimental pressure and heat pain ratings compared with placebo, which became statistically significant when the sample was stratified according to the COMT high activity, low pain sensitive haplotype: 118 a considerable beneficial effect of propranolol on pain perception was noted in subjects not carrying this haplotype, a diminished benefit was observed in the heterozygotes, and no benefit was noted in the homozygotes. These findings corroborate that COMT gene polymorphisms contributes to the variable pharmacodynamic responses to propranolol in patients with chronic musculoskeletal pain, probably as a result of variation in baseline levels of $\beta_{2} / \beta_{3}$-adrenergic signalling.

This sequence of discoveries provides an excellent illustration of how a genetic marker identified in human association studies can be investigated in cellular molecular studies, and confirmed in animal models to identify a putative drug that can be tested in a human clinical trial for safety and efficacy (Figure 1 ). This process not only identified selective $\beta_{2} / \beta_{3}$ adrenergic receptor antagonists as novel candidates for treatment of chronic pain conditions, but also provided evidence that COMT haplotypes can serve as genetic predictors of treatment outcomes, thus enabling the identification of subgroups of patients who are likely to benefit from propranolol therapy. Although the initial clinical pharmacogenomic studies have been conducted on a TMD population, $\beta_{2} / \beta_{3}$-adrenergic receptor antagonists will probably be effective in treating other musculoskeletal pain conditions, and therefore this approach could represent a general example of how to identify genetic markers and new therapeutic targets for human musculoskeletal pain in future studies. 


\section{Heuristic model of pain conditions}

Given the complexity of the human pain phenotypes, greater emphasis is needed in accounting for the contribution of gene, environment and demographic interactions to disease models and drug responses. Manifestation of a pain state at a certain time is triggered by the combination of endogenous and exogenous signals, such as the expression of enzymes that control catecholamine levels and perceived psychological distress. Historically, the relative contribution of 'nature versus nurture' to common clinical conditions has been debated, but that both genetic and environmental factors contribute substantially and interactively to complex traits like pain is now commonly accepted. A heuristic model that illustrates these relationships is presented in Figure 2.

Multiple genetic risk factors contribute to individual variations in psychological distress and sensitivity to pain. These functional allelic variations, common and rare, mediate differential gene expression and activate associated biological pathways that lead to the manifestation of related endophenotypes. On the other hand, pain endophenotypes are also shaped by environmental risk factors like injury, and exposure to physical and psychological stressors. These environmental factors promote changes in DNA methylation patterns, which in turn change the expression of pain related genes and biological pathways in a temporallydependent manner. Thus, together, both environmental risk factors and genetic variants affect the expression of biological pathways and interact to produce pain states. Further accumulation of environmental exposures results in the induction of long-lasting epigenetic changes based on altered methylation patterns. On a vulnerable genetic background, genetic and environmental factors interact to evoke gene expression patterns that enable the transition from an acute pain state to a chronic pain state, which can manifest as pain conditions such as LBP, TMD, CWP and fibromyalgia. The biological processes that lead to a chronic pain state can further increase sensitivity to painful stimuli and stress levels, ${ }^{4}$ modifying expression of pain-related genes and creating a pathological pain cycle. Importantly, demographic factors, including age and sex, also have a great influence on gene expression and thus interact with genetic and environmental risk factors to determine susceptibility to various pain states.

Our heuristic model suggests that multivariable interactions are expected between genetic, environmental, and demographic factors contributing to both acute and chronic pain states. Recording and measuring these variables in a careful way can be a challenge, ${ }^{3}$ and assessing their interaction poses an even greater challenge. Both assessment methods and statistical methodologies are under development that will permit the integration of intermediate phenotypes, genetic factors, and exposure to environmental risk factors into predictive models. Such models will enable the identification of novel subpopulations of patients with musculoskeletal pain and novel subgroup specific therapeutic targets, and inform treatment decisions, thus moving the pain management field towards tailored personalized medicine.

\section{Conclusions}

Common musculoskeletal pain conditions such as LBP, TMD, CWP, and fibromyalgia are complex conditions that are heterogeneous in clinical manifestation. These disorders result 
from an interaction between quantifiable phenotypic domains and genetic variables that are expressed in response to a variety of physical and psychological environment exposures. Studies have begun to unravel the genetic architecture and associated biological pathways that contribute to the clinical manifestations of these conditions. The identification of causal genetic variants based on genetic association studies in humans is proving effective in identifying biological pathways of vulnerability and new therapeutic targets for specific subpopulations of patients, moving us one step closer to operationalizing the concept of personalized medicine.

\section{Acknowledgments}

The authors' work is supported in part by grants from NIDCR, NIA and NINDS, R01-DE16558, U01-DE017018, 1K12DSE022793, AG033906, and P01 NS045685. The authors are grateful to Kirsten Ambrose for assistance with preparation of this manuscript.

\section{References}

1. Relieving Pain in America: A Blueprint for Transforming Prevention, Care, Education, and Research. 1st edn. The National Academies Press; 2011. Committee on Advancing Pain Research, Care and Education, Institute of Medicine.

2. McBeth J, Jones K. Epidemiology of chronic musculoskeletal pain. Best Pract. Res. Clin. Rheumatol. 2007; 21:403-425. [PubMed: 17602991]

3. Slade GD, et al. Study methods, recruitment, sociodemographic findings, and demographic representativeness in the OPPERA study. J. Pain. 2011; 12(Suppl.):T12-T26. [PubMed: 22074749]

4. Maixner W, et al. Orofacial pain prospective evaluation and risk assessment study-the OPPERA study. J. Pain. 2011; 12(11 Suppl.):T4-T11.e2. [PubMed: 22074751]

5. Diatchenko L, Nackley AG, Slade GD, Fillingim RB, Maixner W. Idiopathic pain disorderspathways of vulnerability. Pain. 2006; 123:226-230. [PubMed: 16777329]

6. Maixner W, Fillingim R, Booker D, Sigurdsson A. Sensitivity of patients with painful temporomandibular disorders to experimentally evoked pain. Pain. 1995; 63:341-351. [PubMed: 8719535]

7. Maixner W, Fillingim R, Sigurdsson A, Kincaid S, Silva S. Sensitivity of patients with painful temporomandibular disorders to experimentally evoked pain: evidence for altered temporal summation of pain. Pain. 1998; 76:71-81. [PubMed: 9696460]

8. Graven-Nielsen T, Arendt-Nielsen L. Assessment of mechanisms in localized and widespread musculoskeletal pain. Nat. Rev. Rheumatol. 2010; 6:599-606. [PubMed: 20664523]

9. Woolf CJ. Central sensitization: implications for the diagnosis and treatment of pain. Pain. 2011; 152(Suppl.):S2-S15. [PubMed: 20961685]

10. Fillingim RB, et al. Potential psychosocial risk factors for chronic TMD: descriptive data and empirically identified domains from the OPPERA case-control study. J. Pain. 2011; 12(Suppl.):T46-T60. [PubMed: 22074752]

11. Ohrbach R, et al. Clinical findings and pain symptoms as potential risk factors for chronic TMD: descriptive data and empirically identified domains from the OPPERA case-control study. J. Pain. 2011; 12(Suppl.):T27-T45. [PubMed: 22074750]

12. Howard KJ, et al. Fibromyalgia syndrome in chronic disabling occupational musculoskeletal disorders: prevalence, risk factors, and posttreatment outcomes. J. Occup. Environ. Med. 2010; 52:1186-1191. [PubMed: 21124244]

13. Jones GT, et al. Role of road traffic accidents and other traumatic events in the onset of chronic widespread pain: results from a population-based prospective study. Arthritis Care Res. (Hoboken). 2011; 63:696-701. [PubMed: 21425478]

14. Tchivileva IE, et al. Signaling pathways mediating $\beta_{3}$-adrenergic receptor-induced production of interleukin-6 in adipocytes. Mol. Immunol. 2009; 46:2256-2266. [PubMed: 19477016] 
15. Kehlet H, Jensen TS, Woolf CJ. Persistent postsurgical pain: risk factors and prevention. Lancet. 2006; 367:1618-1625. [PubMed: 16698416]

16. Diatchenko L, et al. Genetic basis for individual variations in pain perception and the development of a chronic pain condition. Hum. Mol. Genet. 2005; 14:135-143. [PubMed: 15537663]

17. Diatchenko L, Nackley AG, Tchivileva IE, Shabalina SA, Maixner W. Genetic architecture of human pain perception. Trends Genet. 2007; 23:605-613. [PubMed: 18023497]

18. Gottesman II, Gould TD. The endophenotype concept in psychiatry: etymology and strategic intentions. Am. J. Psychiatry. 2003; 160:636-645. [PubMed: 12668349]

19. Turk DC, et al. Core outcome domains for chronic pain clinical trials: IMMPACT recommendations. Pain. 2003; 106:337-345. [PubMed: 14659516]

20. Gracely RH, Dubner R. Reliability and validity of verbal descriptor scales of painfulness. Pain. 1987; 29:175-185. [PubMed: 3614956]

21. Jensen MP, Karoly P, Braver S. The measurement of clinical pain intensity: a comparison of six methods. Pain. 1986; 27:117-126. [PubMed: 3785962]

22. Stone AA, Broderick JE, Schneider S, Schwartz JE. Expanding options for developing outcome measures from momentary assessment data. Psychosom. Med. 2012; 74:387-397. [PubMed: 22582336]

23. Melzack R. The McGill Pain Questionnaire: major properties and scoring methods. Pain. 1975; 1:277-299. [PubMed: 1235985]

24. Mackey S, et al. Sensory pain qualities in neuropathic pain. J. Pain. 2012; 13:58-63. [PubMed: 22172451]

25. Younger JW, Shen YF, Goddard G, Mackey SC. Chronic myofascial temporomandibular pain is associated with neural abnormalities in the trigeminal and limbic systems. Pain. 2010; 149:222228. [PubMed: 20236763]

26. Wand BM, Chiffelle LA, O'Connell NE, McAuley JH, Desouza LH. Self-reported assessment of disability and performance-based assessment of disability are influenced by different patient characteristics in acute low back pain. Eur. Spine J. 2010; 19:633-640. [PubMed: 19851791]

27. van Abbema R, et al. Factors associated with functional capacity test results in patients with nonspecific chronic low back pain: a systematic review. J. Occup. Rehabil. 2011; 21:455-473. [PubMed: 21516301]

28. Durand MJ, Brassard B, Hong QN, Lemaire J, Loisel P. Responsiveness of the physical work performance evaluation, a functional capacity evaluation, in patients with low back pain. J. Occup. Rehabil. 2008; 18:58-67. [PubMed: 18181009]

29. Valkeinen H, et al. Physical fitness in postmenopausal women with fibromyalgia. Int. J. Sports Med. 2008; 29:408-413. [PubMed: 17960505]

30. de Bruijn ST, et al. Relevance of physical fitness levels and exercise-related beliefs for selfreported and experimental pain in fibromyalgia: an explorative study. J. Clin. Rheumatol. 2011; 17:295-301. [PubMed: 21869713]

31. McLoughlin MJ, Stegner AJ, Cook DB. The relationship between physical activity and brain responses to pain in fibromyalgia. J. Pain. 2011; 12:640-651. [PubMed: 21330218]

32. Alschuler KN, Hoodin F, Murphy SL, Rice J, Geisser ME. Factors contributing to physical activity in a chronic low back pain clinical sample: A comprehensive analysis using continuous ambulatory monitoring. Pain. 2011; 152:2521-2527. [PubMed: 21872993]

33. Kashikar-Zuck S, et al. Actigraphy-based physical activity monitoring in adolescents with juvenile primary fibromyalgia syndrome. J. Pain. 2010; 11:885-893. [PubMed: 20418183]

34. Gatchel RJ, Peng YB, Peters ML, Fuchs PN, Turk DC. The biopsychosocial approach to chronic pain: scientific advances and future directions. Psychol. Bull. 2007; 133:581-624. [PubMed: 17592957]

35. Turk DC, Monarch ES, Williams AD. Psychological evaluation of patients diagnosed with fibromyalgia syndrome: a comprehensive approach. Rheum. Dis. Clin. North Am. 2002; 28:219233. [PubMed: 12122915]

36. Harkness EF, Macfarlane GJ, Nahit E, Silman AJ, McBeth J. Mechanical injury and psychosocial factors in the work place predict the onset of widespread body pain: a two-year prospective study 
among cohorts of newly employed workers. Arthritis Rheum. 2004; 50:1655-1664. [PubMed: 15146437]

37. Linton SJ. A review of psychological risk factors in back and neck pain. Spine. 2000; 25:11481156. [PubMed: 10788861]

38. Gupta A, et al. The role of psychosocial factors in predicting the onset of chronic widespread pain: results from a prospective population-based study. Rheumatology (Oxford). 2007; 46:666-671. [PubMed: 17085772]

39. McBeth J, Macfarlane GJ, Benjamin S, Silman AJ. Features of somatization predict the onset of chronic widespread pain: results of a large population-based study. Arthritis Rheum. 2001; 44:940-946. [PubMed: 11315933]

40. Jones GT, Power C, Macfarlane GJ. Adverse events in childhood and chronic widespread pain in adult life: results from the 1958 British Birth Cohort Study. Pain. 2009; 143:92-96. [PubMed: 19304391]

41. Aggarwal VR, Macfarlane GJ, Farragher TM, McBeth J. Risk factors for onset of chronic orofacial pain-results of the North Cheshire oro-facial pain prospective population study. Pain. 2010; 149:354-359. [PubMed: 20304556]

42. Dunn KM, Jordan KP, Mancl L, Drangsholt MT, Le RL. Trajectories of pain in adolescents: a prospective cohort study. Pain. 2011; 152:66-73. [PubMed: 20971561]

43. Epker J, Gatchel RJ, Ellis E 3rd. A model for predicting chronic TMD: practical application in clinical settings. J. Am. Dent. Assoc. 1999; 130:1470-1475. [PubMed: 10570591]

44. Jones GT, et al. Predicting persistent disabling low back pain in general practice: a prospective cohort study. Br. J. Gen. Pract. 2006; 56:334-341. [PubMed: 16638248]

45. Rolke R, et al. Quantitative sensory testing: a comprehensive protocol for clinical trials. Eur. J. Pain. 2006; 10:77-88. [PubMed: 16291301]

46. Maier C, et al. Quantitative sensory testing in the German Research Network on Neuropathic Pain (DFNS): somatosensory abnormalities in 1,236 patients with different neuropathic pain syndromes. Pain. 2010; 150:439-450. [PubMed: 20627413]

47. Rehm SE, et al. A cross-sectional survey of 3,035 patients with fibromyalgia: subgroups of patients with typical comorbidities and sensory symptom profiles. Rheumatology (Oxford). 2010; 49:1146-1152. [PubMed: 20236955]

48. Pfau DB, Rolke R, Nickel R, Treede RD, Daublaender M. Somatosensory profiles in subgroups of patients with myogenic temporomandibular disorders and fibromyalgia syndrome. Pain. 2009; 147:72-83. [PubMed: 19767146]

49. Egloff N, Sabbioni ME, Salathe C, Wiest R, Juengling FD. Nondermatomal somatosensory deficits in patients with chronic pain disorder: clinical findings and hypometabolic pattern in FDG-PET. Pain. 2009; 145:252-258. [PubMed: 19500908]

50. Leffler AS, Hansson P, Kosek E. Somatosensory perception in patients suffering from long-term trapezius myalgia at the site overlying the most painful part of the muscle and in an area of pain referral. Eur. J. Pain. 2003; 7:267-276. [PubMed: 12725850]

51. Wallin M, Liedberg G, Borsbo B, Gerdle B. Thermal detection and pain thresholds but not pressure pain thresholds are correlated with psychological factors in women with chronic whiplash-associated pain. Clin. J. Pain. 2012; 28:211-221. [PubMed: 21750459]

52. Staud R, Weyl EE, Price DD, Robinson ME. Mechanical and heat hyperalgesia highly predict clinical pain intensity in patients with chronic musculoskeletal pain syndromes. J. Pain. 2012; 13:725-735. [PubMed: 22739051]

53. Edwards RR, Sarlani E, Wesselmann U, Fillingim RB. Quantitative assessment of experimental pain perception: multiple domains of clinical relevance. Pain. 2005; 114:315-319. [PubMed: 15777856]

54. Arendt-Nielsen L, Petersen-Felix S. Wind-up and neuroplasticity: is there a correlation to clinical pain? Eur. J. Anaesthesiol. Suppl. 1995; 10:1-7. [PubMed: 7641635]

55. Eide PK. Wind-up and the NMDA receptor complex from a clinical perspective. Eur. J. Pain. 2000; 4:5-15. [PubMed: 10833550]

56. Price DD, et al. Enhanced temporal summation of second pain and its central modulation in fibromyalgia patients. Pain. 2002; 99:49-59. [PubMed: 12237183] 
57. Yarnitsky D, et al. Recommendations on terminology and practice of psychophysical DNIC testing. Eur. J. Pain. 2010; 14:339. [PubMed: 20227310]

58. King CD, et al. Deficiency in endogenous modulation of prolonged heat pain in patients with irritable bowel syndrome and temporomandibular disorder. Pain. 2009; 143:172-178. [PubMed: 19278784]

59. Staud R, Robinson ME, Vierck CJ Jr, Price DD. Diffuse noxious inhibitory controls (DNIC) attenuate temporal summation of second pain in normal males but not in normal females or fibromyalgia patients. Pain. 2003; 101:167-174. [PubMed: 12507711]

60. Staud R. Autonomic dysfunction in fibromyalgia syndrome: postural orthostatic tachycardia. Curr. Rheumatol. Rep. 2008; 10:463-466. [PubMed: 19007537]

61. Light KC, et al. Adrenergic dysregulation and pain with and without acute beta-blockade in women with fibromyalgia and temporomandibular disorder. J. Pain. 2009; 10:542-552. [PubMed: 19411061]

62. Giske L, et al. Attenuated adrenergic responses to exercise in women with fibromyalgia-a controlled study. Eur. J. Pain. 2008; 12:351-360. [PubMed: 17827042]

63. Martinez-Lavin M. Biology and therapy of fibromyalgia. Stress, the stress response system, and fibromyalgia. Arthritis Res. Ther. 2007; 9:216. [PubMed: 17626613]

64. Perry F, Heller PH, Kamiya J, Levine JD. Altered autonomic function in patients with arthritis or with chronic myofascial pain. Pain. 1989; 39:77-84. [PubMed: 2812855]

65. Kelemen J, Lang E, Balint G, Trocsanyi M, Muller W. Orthostatic sympathetic derangement of baroreflex in patients with fibromyalgia. J. Rheumatol. 1998; 25:823-825. [PubMed: 9558200]

66. Reyes del Paso GA, Garrido S, Pulgar A, Duschek S. Autonomic cardiovascular control and responses to experimental pain stimulation in fibromyalgia syndrome. J. Psychosom. Res. 2011; 70:125-134. [PubMed: 21262414]

67. Gockel M, Lindholm H, Niemisto L, Hurri H. Perceived disability but not pain is connected with autonomic nervous function among patients with chronic low back pain. J. Rehabil. Med. 2008; 40:355-358. [PubMed: 18461260]

68. Furlan R, et al. Abnormalities of cardiovascular neural control and reduced orthostatic tolerance in patients with primary fibromyalgia. J. Rheumatol. 2005; 32:1787-1793. [PubMed: 16142879]

69. Hamaty D, et al. The plasma endorphin, prostaglandin and catecholamine profile of patients with fibrositis treated with cyclobenzaprine and placebo: a 5-month study. J. Rheumatol. Suppl. 1989; 19:164-168. [PubMed: 2532682]

70. Legangneux E, et al. Cerebrospinal fluid biogenic amine metabolites, plasma-rich platelet serotonin and $\left[{ }^{3} \mathrm{H}\right]$ imipramine reuptake in the primary fibromyalgia syndrome. Rheumatology (Oxford). 2001; 40:290-296. [PubMed: 11285376]

71. Yunus MB, Dailey JW, Aldag JC, Masi AT, Jobe PC. Plasma and urinary catecholamines in primary fibromyalgia: a controlled study. J. Rheumatol. 1992; 19:95-97. [PubMed: 1556708]

72. Maixner W, et al. Potential autonomic risk factors for chronic TMD: descriptive data and empirically identified domains from the OPPERA case-control study. J. Pain. 2011; 12(Suppl.):T75-T91. [PubMed: 22074754]

73. Hastie BA, et al. Cluster analysis of multiple experimental pain modalities. Pain. 2005; 116:227237. [PubMed: 15964682]

74. Scholz J, et al. A novel tool for the assessment of pain: validation in low back pain. PLoS Med. 2009; 6:e1000047. [PubMed: 19360087]

75. Suvinen TI, Reade PC, Hanes KR, Kononen M, Kemppainen P. Temporomandibular disorder subtypes according to self-reported physical and psychosocial variables in female patients: a reevaluation. J. Oral Rehabil. 2005; 32:166-173. [PubMed: 15707426]

76. Velly AM, Philippe P, Gornitsky M. Heterogeneity of temporomandibular disorders: cluster and case-control analyses. J. Oral Rehabil. 2002; 29:969-979. [PubMed: 12421328]

77. Wilson HD, Starz TW, Robinson JP, Turk DC. Heterogeneity within the fibromyalgia population: theoretical implications of variable tender point severity ratings. J. Rheumatol. 2009; 36:27952801. [PubMed: 19918043]

78. Giesecke T, et al. Subgrouping of fibromyalgia patients on the basis of pressure-pain thresholds and psychological factors. Arthritis Rheum. 2003; 48:2916-2922. [PubMed: 14558098] 
79. Loevinger BL, Shirtcliff EA, Muller D, Alonso C, Coe CL. Delineating psychological and biomedical profiles in a heterogeneous fibromyalgia population using cluster analysis. Clin. Rheumatol. 2012; 31:677-685. [PubMed: 22200814]

80. Hastie, T.; Tibshirani, R.; Friedman, J. The Elements of Statistical Learning: Data Mining, Inference, and Prediction. 2nd edn. New York: Springer; 2009.

81. Kato K, Sullivan PF, Pedersen NL. Latent class analysis of functional somatic symptoms in a population-based sample of twins. J. Psychosom. Res. 2010; 68:447-453. [PubMed: 20403503]

82. Fejer R, Hartvigsen J, Kyvik KO. Heritability of neck pain: a population-based study of 33,794 Danish twins. Rheumatology (Oxford). 2006; 45:589-594. [PubMed: 16332950]

83. Williams FM, Spector TD, Macgregor AJ. Pain reporting at different body sites is explained by a single underlying genetic factor. Rheumatology (Oxford). 2010; 49:1753-1755. [PubMed: 20525736]

84. Markkula R, et al. Clustering of symptoms associated with fibromyalgia in a Finnish Twin Cohort. Eur. J. Pain. 2009; 13:744-750. [PubMed: 18938094]

85. Vargas-Alarcon G, et al. Catechol-O-methyltransferase gene haplotypes in Mexican and Spanish patients with fibromyalgia. Arthritis Res. Ther. 2007; 9:R110. [PubMed: 17961261]

86. Gursoy S, et al. Significance of catechol-O-methyltransferase gene polymorphism in fibromyalgia syndrome. Rheumatol. Int. 2003; 23:104-107. [PubMed: 12739038]

87. Matsuda JB, et al. Serotonin receptor (5-HT 2A) and catechol-O-methyltransferase (COMT) gene polymorphisms: triggers of fibromyalgia? Rev. Bras. Reumatol. 2010; 50:141-149. [PubMed: 21125150]

88. Barbosa FR, et al. Influence of catechol-O-methyltransferase (COMT) gene polymorphisms in pain sensibility of Brazilian fibromialgia patients. Rheumatol. Int. 2012; 32:427-430. [PubMed: 21120493]

89. Cohen H, Neumann L, Glazer Y, Ebstein RP, Buskila D. The relationship between a common catechol-O-methyltransferase (COMT) polymorphism val(158) met and fibromyalgia. Clin. Exp. Rheumatol. 2009; 27(Suppl. 56):S51-S56. [PubMed: 20074440]

90. Martínez-Jauand M, et al. Pain sensitivity in fibromyalgia is associated with catechol-Omethyltransferase (COMT) gene. Eur. J. Pain. 2013; 17:16-27. [PubMed: 22528689]

91. Smith SB, et al. Potential genetic risk factors for chronic TMD: genetic associations from the OPPERA case-control study. J. Pain. 2011; 12(Suppl.):T92-T101. [PubMed: 22074755]

92. Hocking LJ, et al. Genetic variation in the $\beta_{2}$-adrenergic receptor but not catecholamine-Omethyltransferase predisposes to chronic pain: results from the 1958 British Birth Cohort Study. Pain. 2010; 149:143-151. [PubMed: 20167428]

93. Xiao Y, He W, Russell IJ. Genetic polymorphisms of the $\beta_{2}$-adrenergic receptor relate to guanosine protein-coupled stimulator receptor dysfunction in fibromyalgia syndrome. J. Rheumatol. 2011; 38:1095-1103. [PubMed: 21406495]

94. Diatchenko L, et al. Three major haplotypes of the $\beta_{2}$ adrenergic receptor define psychological profile, blood pressure, and the risk for development of a common musculoskeletal pain disorder. Am. J. Med. Genet. B, Neuropsychiatr. Genet. 2006; 141B:449-462. [PubMed: 16741943]

95. Offenbaecher M, et al. Possible association of fibromyalgia with a polymorphism in the serotonin transporter gene regulatory region. Arthritis Rheum. 1999; 42:2482-2488. [PubMed: 10555044]

96. Cohen H, Buskila D, Neumann L, Ebstein RP. Confirmation of an association between fibromyalgia and serotonin transporter promoter region (5-HTTLPR) polymorphism, and relationship to anxiety-related personality traits. Arthritis Rheum. 2002; 46:845-847. [PubMed: 11920428]

97. Carvalho LS, et al. May genetic factors in fibromyalgia help to identify patients with differentially altered frequencies of immune cells? Clin. Exp. Immunol. 2008; 154:346-352. [PubMed: 19037919]

98. Ojima K, Watanabe N, Narita N, Narita M. Temporomandibular disorder is associated with a serotonin transporter gene polymorphism in the Japanese population. Biopsychosoc. Med. 2007; 1:3. [PubMed: 17371573] 
99. Herken $\mathrm{H}$, et al. Possible association of temporomandibular joint pain and dysfunction with a polymorphism in the serotonin transporter gene. Am. J. Orthod. Dentofacial Orthop. 2001; 120:308-313. [PubMed: 11552131]

100. Bondy B, et al. The T102C polymorphism of the 5-HT2A-receptor gene in fibromyalgia. Neurobiol. Dis. 1999; 6:433-439. [PubMed: 10527809]

101. Mergener M, Becker RM, dos Santos AF, dos Santos GA, de Andrade FM. Influence of the interaction between environmental quality and T102C SNP in the HTR2A gene on fibromyalgia susceptibility. Rev. Bras. Reumatol. 2011; 51:594-602. [PubMed: 22124593]

102. Mutlu N, Erdal ME, Herken H, Oz G, Bayazit YA. T102C polymorphism of the 5-HT2A receptor gene may be associated with temporomandibular dysfunction. Oral Dis. 2004; 10:349-352. [PubMed: 15533210]

103. Burda C, Cox F, Osborne P. Histocompatibility antigens in the fibrositis (fibromyalgia) syndrome. Clin. Exp. Rheumatol. 1986; 4:355-358. [PubMed: 3491715]

104. Branco JC, Tavares V, Abreu I, Correia MM, Caetano JAM. HLA studies in fibromyalgia. J. Muscoskelet. Pain. 1996; 4:21-27.

105. Horven S, Stiles TC, Holst A, Moen T. HLA antigens in primary fibromyalgia syndrome. J. Rheumatol. 1992; 19:1269-1270. [PubMed: 1404164]

106. Blanco I, et al. $a_{1}$-antitrypsin polymorphism in fibromyalgia syndrome patients from the Asturias province in Northern Spain: a significantly higher prevalence of the PI*Z deficiency allele in patients than in the general population. J. Muscoskelet. Pain. 2006; 14:5-12.

107. Schmechel DE, Edwards CL. Fibromyalgia, mood disorders, and intense creative energy: AlAT polymorphisms are not always silent. Neurotoxicology. 2012; 33:1454-1472. [PubMed: 22414631]

108. Vossen $\mathrm{H}$, et al. The genetic influence on the cortical processing of experimental pain and the moderating effect of pain status. PLoS ONE. 2010; 5:e13641. [PubMed: 21049025]

109. Desmeules J, et al. Psychological distress in fibromyalgia patients: a role for catechol-O-methyltransferase Val158met polymorphism. Health Psychol. 2012; 31:242-249. [PubMed: 21895373]

110. Gursoy S, Erdal E, Herken H, Madenci E, Alasehirli B. Association of T102C polymorphism of the 5-HT2A receptor gene with pyschiatric status in fibromyalgia syndrome. Rheumatol. Int. 2001; 21:58-61. [PubMed: 11732859]

111. Feng $\mathrm{J}$, et al. Missense mutations in the $M E F V$ gene are associated with fibromyalgia syndrome and correlate with elevated IL-1 $\beta$ plasma levels. PLoS ONE. 2009; 4:e8480. [PubMed: 20041150]

112. Slade GD, et al. Study methods, recruitment, sociodemographic findings, and demographic representativeness in the OPPERA study. J. Pain. 2011; 12(Suppl.):T12-T26. [PubMed: 22074749]

113. Teslovich TM, et al. Biological, clinical and population relevance of 95 loci for blood lipids. Nature. 2010; 466:707-713. [PubMed: 20686565]

114. Kathiresan S, Srivastava D. Genetics of human cardiovascular disease. Cell. 2012; 148:12421257. [PubMed: 22424232]

115. Diatchenko L, et al. Catechol-O-methyltransferase gene polymorphisms are associated with multiple pain-evoking stimuli. Pain. 2006; 125:216-224. [PubMed: 16837133]

116. Segall SK, et al. Comt1 genotype and expression predicts anxiety and nociceptive sensitivity in inbred strains of mice. Genes Brain Behav. 2010; 9:933-946. [PubMed: 20659173]

117. Nackley A, et al. Catechol-O-methyltransferase inhibition increases pain sensitivity through activation of both $\beta_{2}$ - and $\beta_{3}$-adrenergic receptors. Pain. 2007; 128:199-208. [PubMed: 17084978]

118. Tchivileva IE, et al. Effect of catechol-O-methyltransferase polymorphism on response to propranolol therapy in chronic musculoskeletal pain: a randomized, double-blind, placebocontrolled, crossover pilot study. Pharmacogenet. Genomics. 2010; 20:239-248. [PubMed: 20216107]

119. Nackley A, et al. Human catechol-O-methyltransferase haplotypes modulate protein expression by altering mRNA secondary structure. Science. 2006; 314:1930-1933. [PubMed: 17185601] 
120. Kambur O, Mannisto PT. Catechol-O-methyltransferase and pain. Int. Rev. Neurobiol. 2010; 95:227-279. [PubMed: 21095465]

121. Vargas-Alarcon G, et al. Association of adrenergic receptor gene polymorphisms with different fibromyalgia syndrome domains. Arthritis Rheum. 2009; 60:2169-2173. [PubMed: 19565482]

122. Diatchenko L, et al. Three major haplotypes of the $\beta_{2}$ adrenergic receptor define psychological profile, blood pressure, and the risk for development of a common musculoskeletal pain disorder. Am. J. Med. Genet. Part B. 2006; 141B:449-462. [PubMed: 16741943]

123. Finan $\mathrm{PH}$, et al. COMT moderates the relation of daily maladaptive coping and pain in fibromyalgia. Pain. 2011; 152:300-307. [PubMed: 21130573]

124. Finan PH, et al. Genetic influences on the dynamics of pain and affect in fibromyalgia. Health Psychol. 2010; 29:134-142. [PubMed: 20230086]

125. Jacobsen LM, et al. The COMT rs4680 Met allele contributes to long-lasting low back pain, sciatica and disability after lumbar disc herniation. Eur. J. Pain. 2012; 16:1064-1069. [PubMed: 22337560]

126. Dai F, et al. Association of catechol-O-methyltransferase genetic variants with outcome in patients undergoing surgical treatment for lumbar degenerative disc disease. Spine J. 2010; 10:949-957. [PubMed: 20863768]

127. Omair A, Lie B, Reikeras O, Holden M, Brox J. Genetic contribution of catechol-Omethyltransferase variants in treatment outcome of low back pain: a prospective genetic association study. BMC Musculoskelet. Disord. 2012; 13:76. [PubMed: 22612913]

128. Slade G, Diatchenko L, Ohrbach R, Maixner W. Orthodontic treatment, genetic factors, and risk of temporomandibular disorder. Semin. Orthod. 2008; 14:146-156. [PubMed: 18663384]

129. Yunus MB. Genetic factors in fibromyalgia syndrome. Z. Rheumatol. 1998; 57(Suppl. 2):S61S62.

130. Holliday KL, et al. Genetic variation in neuroendocrine genes associates with somatic symptoms in the general population: results from the EPIFUND study. J. Psychosom. Res. 2010; 68:469474. [PubMed: 20403506] 


\section{Key points}

- Musculoskeletal pain conditions such as low back pain, chronic widespread pain, fibromyalgia and temporomandibular joint disorders are highly prevalent

- These conditions have measurable phenotypic signatures, which are heterogeneous in nature

- Musculoskeletal pain conditions have a genetic basis, with both common and rare genetic variants contributing to the conditions and associated endophenotypes

- Physical and psychological environmental exposures can produce epigenetic effects that alter gene expression, biological pathway activity, and thus the manifestation of clinical phenotypes of musculoskeletal pain conditions

- Genetic association studies combined with in vitro and in vivo follow-up studies can identify effective therapeutic agents for the treatment of large subpopulations of patients with musculoskeletal pain conditions 


\section{Review criteria}

A search for original articles published between 1990 and 2012 and focusing on musculoskeletal pain was performed in MEDLINE and PubMed. The search terms used were "psychological factors", "psychological distress", "temporomandibular disorders", "chronic widespread pain", "low back pain", "fibromyalgia", "musculoskeletal pain", "pain sensitivity", "quantitative sensory testing", "polymorphism" and "association studies" alone and in various combinations. All articles identified were English-language, full-text papers and abstracts. We also searched the reference lists of identified articles for further relevant papers. The reference list was last updated October 2012. 


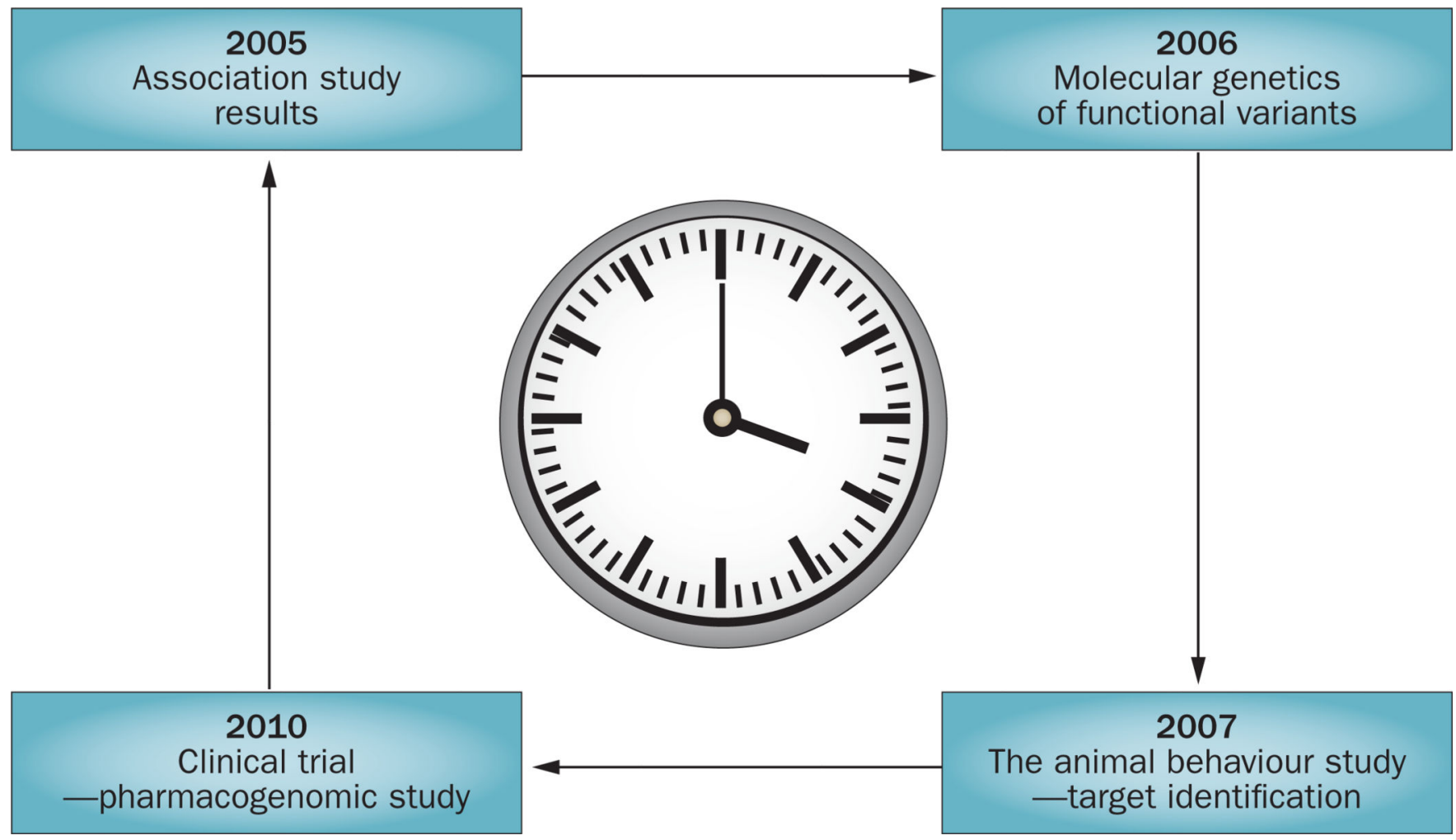

Figure 1.

The translational clock - a schematic representation of a novel and rapid approach to identification of new therapeutic targets in commonly observed persistent pain conditions. The identification of COMT as a therapeutic target in TMD is used as an example, to provide an idea of the timescales involved. Identification of common genetic variants associated with risk of developing a chronic pain condition can reveal putative causal biological pathways. In our example, in 2005, COMT haplotypes were associated with experimental pain and myogenous TMD. ${ }^{16}$ Subsequent in vitro and in vivo proof-ofprinciple studies should demonstrate that the pharmacological or genetic modification of the identified pathways can produce cellular phenotypes and animal behaviours consistent with the human pain condition. For example, in 2006, a cellular molecular study demonstrated that COMT levels and activity were associated with COMT haplotypes. ${ }^{119}$ In 2007 , pharmacological inhibition of COMT in rats was shown to increase sensitivity to pain, a response abrogated by $\beta_{2} / \beta_{3}$-adrenergic antagonists, ${ }^{117}$ thus, identifying $\beta$-adrenergic receptors as therapeutic targets. Following positive proof-of-principle studies, a clinical proof-of-concept trial can be initiated using either existing or novel pharmacological agents. In our example, the nonselective $\beta$-adrenergic antagonist propranolol was the subject of a 2010 clinical trial in patients with TMD. ${ }^{118}$ This reverse translational process results in the rapid discovery and testing of interventions that modify the identified biological pathways that determine susceptibility. Abbreviations: COMT, catechol O-methyltransferase, TMD, temporomandibular joint disorder. 


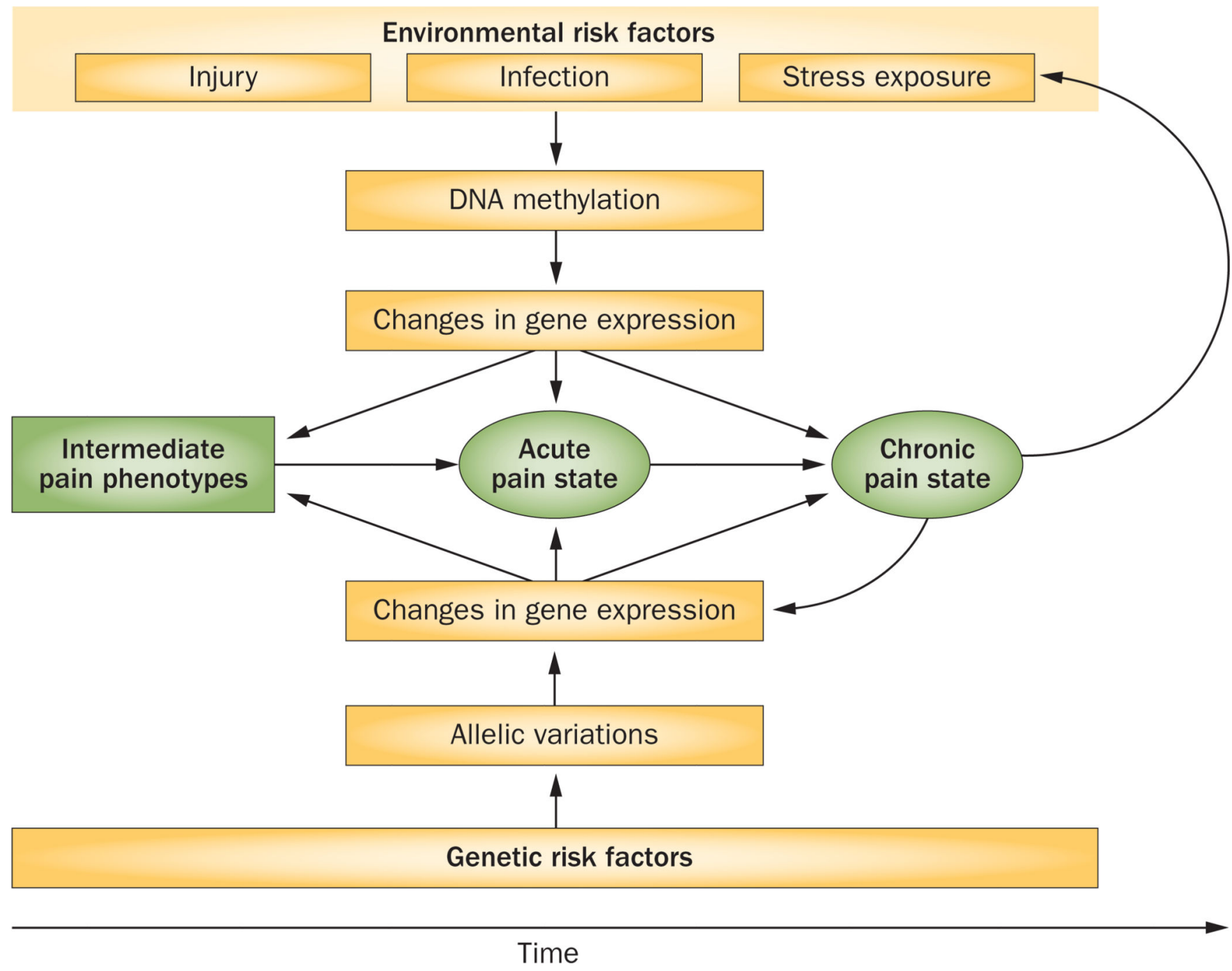

Figure 2.

The pathological chronic pain circle. Genetic and environment interactions contribute to the development of pain conditions. Allelic variation underlies functional differences in expression or activity of pain-related gene products and activation of associated biological pathways, leading to manifestation of related pain endophenotypes. In addition, pain endophenotypes are shaped by exposure to environmental factors, which result in alteration of DNA methylation patterns that, in turn, change the expression of pain-related genes and the activity of associated biological pathways. With prolonged exposure to environmental stimuli that induce long-term methylation patterns - that is, long-lasting changes in DNA methylation - on a background of genetic susceptibility, altered gene expression profiles enable the transition of an acute pain state to a chronic pain state. The biological processes that lead to the chronic pain state further increase sensitivity to painful stimuli and perceived levels of stress, which further modifies pain-related gene expression, creating a pathological pain cycle. 


\section{Table 1}

Elements of clinical phenotyping and QST endophenotyping in pain conditions*

\begin{tabular}{llll}
\hline Clinical pain & Physical function/disability & Psychosocial functioning & QST \\
\hline Global pain severity & Condition-specific functional limitations & Global psychological symptoms & Nonpain somatosensation \\
\hline $\begin{array}{l}\text { Pain intensity and } \\
\text { unpleasantness }\end{array}$ & General pain-related disability & Somatic awareness & Generalized hyperalgesia \\
\hline Temporal characteristics & Generic measures of function/disability & Stress and life events & Pain facilitatory function \\
\hline Perceptual characteristics & Performance-based measures & Pain-related cognitions and pain \\
coping
\end{tabular}


Table 2

Genes implicated in human musculoskeletal pain conditions

\begin{tabular}{|c|c|c|}
\hline Gene or genetic region & Disease & Associated intermediate phenotype \\
\hline$A D R B 2\left(\beta_{2}\right.$ adrenergic receptor $)$ & $\begin{array}{l}\text { Fibromyalgia }^{93,121} \\
\text { CWP }^{92} \\
\text { TMD }^{122}\end{array}$ & $\begin{array}{l}\text { Psychological distress; }{ }^{122} \text { blood pressure }{ }^{122} \text { sleep dysfunction in } \\
\text { fibromyalgia; }{ }^{93} \text { low PBMC basal and isoproterenol-stimulated cAMP } \\
\text { levels }{ }^{93}\end{array}$ \\
\hline COMT (Catechol O-methyltransferase) & $\begin{array}{l}\text { Fibromyalgia }{ }^{85-90} \\
\text { TMD }^{16}\end{array}$ & $\begin{array}{l}\text { In fibromyalgia: pain catastrophizing; }{ }^{123} \text { increased pain level during } \\
\text { elevated pain attention; }{ }^{123} \text { thermal and pressure pain sensitivity; }{ }^{90} \\
\text { psychological distress; }{ }^{109} \text { increase number of tender points in TPC; } 89 \\
\text { pain and positive affect interaction; }{ }^{124} \text { and FIQ-defined pain, fatigue, } \\
\text { sleep disturbance, morning stiffness and disability }{ }^{85,88} \\
\text { In LBP: altered cortical pain processing, }{ }^{108} \text { increased pain intensity, }^{125} \\
\text { less favourable treatment outcome }{ }^{125-127} \\
\text { In TMD: interaction with orthodontic treatment }{ }^{128} \text { and reduced } \\
\text { efficacy of propranolol treatment of TMD; }{ }^{118} \text { experimental pain }^{\text {sensitivity }}{ }^{16}\end{array}$ \\
\hline HLA/MHC region & Fibromyalgia $103,104,129$ & NA \\
\hline $\begin{array}{l}H T R 2 A \text { (5-hydroxytryptamine receptor } 2 \mathrm{~A} \text {, } \\
\text { also known as serotonin receptor } 2 \mathrm{~A} \text { ) }\end{array}$ & $\begin{array}{l}\text { Fibromyalgia }{ }^{100,101} \\
\text { TMD }^{102}\end{array}$ & $\begin{array}{l}\text { Tender point count }{ }^{100} \text { and pain intensity in fibromyalgia; }{ }^{110} \text { increased } \\
\text { somatic symptom counts; }{ }^{130} \text { reduced perception of environmental } \\
\text { quality; }{ }^{101} \text { increased in SCL-90-R total score and subscales scores for } \\
\text { somatic awareness, anxiety, psychosis, obsessive-compulsive } \\
\text { behaviour, hostility, global severity index, interpersonal sensitivity, } \\
\text { phobic anxiety, depression }\end{array}$ \\
\hline SERPINA1 ( $\mathrm{a}_{1}$-antitrypsin $)$ & $\begin{array}{l}\text { Fibromyalgia }{ }^{106,107} \\
\text { CWP }^{130}\end{array}$ & $\begin{array}{l}\text { 'Intense creative energy' risk phenotype }{ }^{107} \text { increased number of } \\
\text { painful body sites }{ }^{130}\end{array}$ \\
\hline $\begin{array}{l}\text { SLC6A4 (sodium-dependent serotonin } \\
\text { transporter) }\end{array}$ & $\begin{array}{l}\text { Fibromyalgia }{ }^{95-97} \\
\text { TMD }^{98,99}\end{array}$ & $\begin{array}{l}\text { Higher BDI and SCL-90-R scores } ;{ }^{95} \text { SCL- } 90 \text { scores for somatic } \\
\text { awareness and anger; } ; 9 \text { TPQ harm avoidance trait } ; 96 \text { increased } \\
\text { salivary cortisol level } ;{ }^{97} \text { increased leukocyte count }{ }^{97}\end{array}$ \\
\hline
\end{tabular}

Abbreviations: BDI, Beck Depression Inventory; CWP, chronic widespread pain; FIQ, Fibromyalgia Impact Questionnaire; LBP, low back pain; NA, not assessed; PBMC, peripheral blood mononuclear cell; SCL-90, Symptom Checklist-90; SCL-90-R, SCL-90-Revised; TMD,

temporomandibular joint disorders; TPC, tender point count; TPQ, Tridimensional Personality Questionnaire. 